\section{REMARKS ON THE NEW MONOTREME FROM NEW GUINEA}

A FEW weeks ago we announced to our readers the A remarkable news of the existence of a mammal of the order Monotremata in New Guinea. The receipt of a separate copy of the description of this animal, just published by Dr. W. Peters and the Marquis G. Doria, ${ }^{1}$ enable us to give a few more particulars of what must be universally regarded as one of the most important zoological discoveries of the period.

Mr. Bruijn, of Ternate, to whom science is indebted for our first acquaintance with this novelty, gives the following details of its discovery in a letter to the Italian naturalist, Dr. Beccari :-

"Two years running my native collectors have brought me word that, according to the Papuan mountaineers, there are a good many mammals in New Guinea, but that they are only hunted there when they are required for food. At first I did not place much confidence in these stories, because I know the litıle value of the reports of the hunters and the natives in general. Nevertheless, I have always told them to look carefully for mammals. The last time they set out I told them, in order to stimulate their zeal, that I knew that a certain animal existed in New Guinea of which I showed them a figure, and that $I$ wished to have it at any price, hoping that in searching for it they woult, perhaps, find other new or littleknown species. The figure which I showed to Joseph and the other huisters was that of an Echidna.

"This year (1876) my men ascended a peak of the Arfaks called Mickirbo, and halted at a spot about the same height above the sea-level as Pjobieda. Here Saleh entered a hut where a piece of a skull of a mammal was offered to him, which he at once thought belonged to the animal which I required. He accepted it and forthwith commenced interrogating the Papuan who had given it to him. The latter told him that the skull belonged to an animal with four legs, with a tail, as large as a dog, and with long harsh fur; he added that these animals were not uncommon on Mount Arfak, and concealed themselves in small caves, and that the Papuans hunted them with dogs, being very fond of their flesh. The skull in question belonged to an animal that had been killed about a month before. Acting upon this information, Saleh set to work to hunt for this animal, but without success. It was only after he had descended from the mountains that a second skull was brought to him, which was still stinking from the fragments of rotten muscles attached to it."

One of these two crania reached the Museo Civico of Genoa, in November last, and constitutes the material upon which Messrs. Peters and Doria, who are engaged on a joint memoir upon the Mammals and Reptiles of New Guinea, have founded their Tachyglossus ${ }^{2}$ FIG. x.-Skull of Tachyglossus of New Guinea. Fig. 2. - \$kull of Tachyglessus of Australia bru'jnii.

It will be observed that this skull, of which a figure is given herewith (Fig. I), copied from that of Messrs. Peters and Doria, wants the greater part of its posterior

$x$ W. Peters e G. Doriz: "Descrizione di una nuova specie di Tachyglossus proveriente dalla Nuova Guinea settentrionale." Ann. Mus. Civ. di St. Nat. di Genova, vol ix. (December 3,1876 )

2 The "Spiny Ant-eater" of Australia is usually called Echiona in scientific nomenclature, but Messrs. Peters and Doria reject this term in favour of Titchyolossus of Illiger, because Echidna was previously applied by Foster in 1778 to a geuus of fishes.

portion, and also the lower jaw. But it is quite perfect enough to enable one to see at a glance that the species must be quite distinct from the Australian Tachyglossus hystrix and $T$. setosus. In the first place the size of the skull is much greater, and the rostrum of the new species is longer by one half, measuring in total length about 6.4 inches, instead of 4.2 inches, as in the Australian animal, ${ }^{1}$ of which a skull is represented (Fig. 2) for comparison. Again, in the Papuan species, the rostrum is
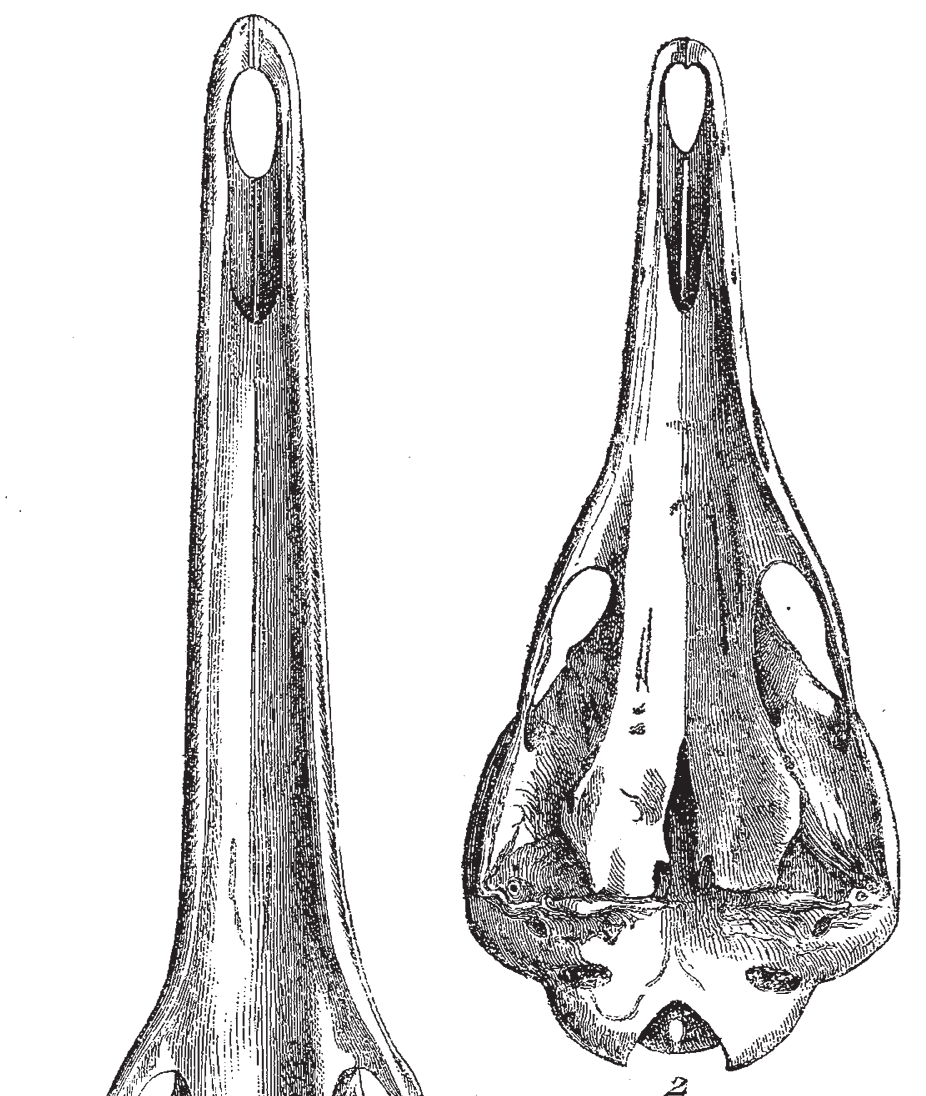
animal must belong to a much larger and quite distinct species, of which we trust it will not be long before perfect examples are received in Europe.

The significance of the discovery of a species of Tachyglossus in New Guinea will be appreciated when we consider that hitherto the Monotremes or Ornithodelphs, which, according to the most recent authorities, constitute not merely a distinct order, but even a separate sub-class of mammals, have been supposed to be at present exclusively restricted to Australia. The two only known genera of Monotremes are Tachyglossus (sive Echidna) and Ornithorhynchus. Of the latter the single known species is peculiar to South-Eastern Australia, of the former, the two species are found, one in South.Eastern Australia, and the other in Tasmania. The whole of the north and west of the Australian continent is, so far as we are at present informed, without any representative of this remarkable group. Looking at these facts, the discovery of a species of Monotreme in New Guinea becomes still more significant, and leads us to expect that when the mountain-ranges of Queensland have been further explored, some representative of the order may still be found lingering in this district, and uniting the newlydiscovered area of distribution with that previously known.

Finally we may remark that the fundamental unity of the Papuan and Australian fauna was already sufficiently obvious by the existence amongst mammals of Macropus and amongst birds of such peculiar genera as Orthonyx and Climacteris in New Guinea. The discovery of Tachyglossus bruijnii is another confirmation of the correctness of this view, as regards zoology, though, as regards the flora of New Guinea, facts, we believe, point rath $\mathrm{r}$ in another direction.

P. L. S.

\section{ON THE TROPICAL FORESTS OF HAMPSHIRE ${ }^{1}$}

\section{II.}

$\mathrm{T}$ has been mentioned that in some of the clays remains of leaves, fruits, and flowers are met with, and I will now proceed to teil you something about them. There are some enlarged drawings here on the wall which I should tell you are not all enlarged to equal scale, and there are trays of specimens on the table.

These leaves are found in various conditions of preservation. In most cases the impression only of the leaves in the clay is met with, but in some cases they are so well preserved that the actual substance has been retained although chemical changes have altered its composition, and it will peel off and blow away. In some of the clays the masses of leaves are so decayed that they cannof be recognised, and are not worth our collecting.

Where the preservation is good we can readily distintinguish the various original textures of the leaves by comparing their general aspect and colour both among themselves and with existing forms. For instance, those which are thick, such as evergreens, thin, as convolvulus, hard, such as oak, or soft, such as lilac, or even velvety, such as the common phlox, can all be recognised. Their colours, in most of the beds, vary from buff to brown, but I need hardly tell you that in no case have we any of the green colouring of the leaves preserved. Whilst these various shades of dark buffs and browns are in many cases the result of chemical change that has taken place after the leaf was covered up, yet I believe that in many cases this change had occurred, at least partially, before the covering up, just as we saw a few weeks ago the changed colours of the fallen leaves of autumn.

In the darker clays the remains are black and com-

I Lecture in connection with the Loan Collection of Scientific Apparatus, given at the South Kensington Museum, December 2, 1876 , by J. Starkie Gardner, F.G.S. Continued from p. 233. pletely carbonised; where this is so the finer venation is indistinct and the remains difficult to save, so that we may discard them unless the outline of the leaf is of unusual form. The darker browns, I take it, indicate hard and evergreen leaves; for instance, the laurtl-like leaves are always of a deep colour, whilst both the thin and the succulent leaves are always of light colour, as in the leaves which we suppose to be fig, some species of smilax, \&c.

No other colours have been met with with one remarkable exception; fragments of a reed-like aspect are found of a deep violet, staining the surrounding clay mauve for a considerable distance.

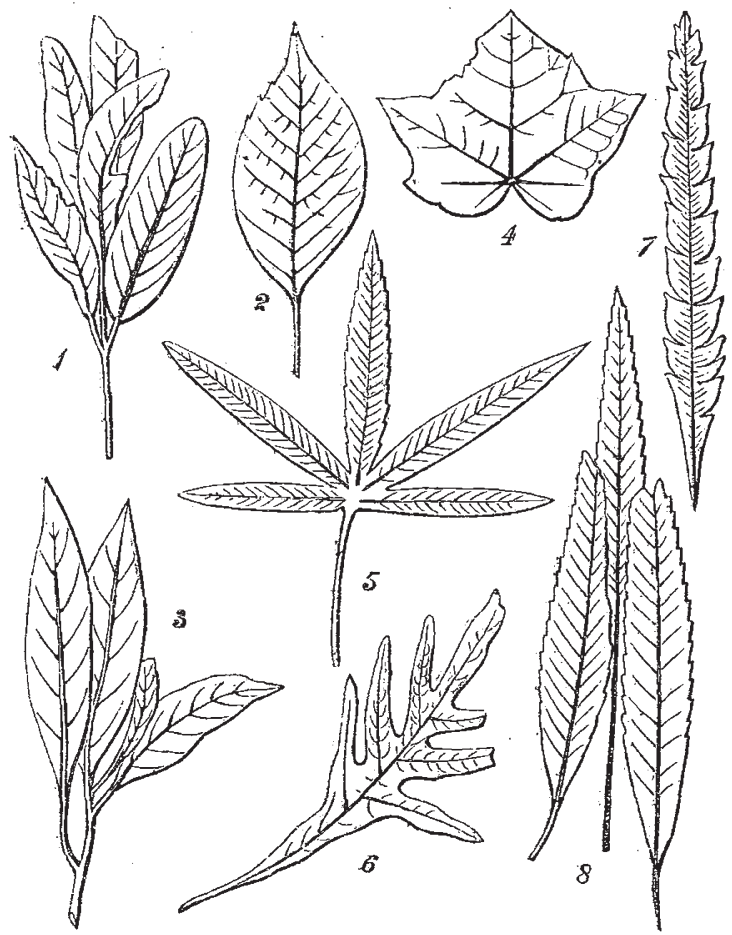

Fig. 4-Leaves of Dicotyledons, From the Lower Barshot Beos. 4 and 2, Fagus: 3, Laurus: 4, Acer; 5 , Aralia (?); 6, Stenocarpus:

I next call attention to the shapes of these leaves; the most cursory examination shows that the differences in shape are very great. Here are drawings of palmate leaves, leaves resembling in general shape the beech, the sub-tropical Dryandra, which, though unfamiliar, have been probably seen by most of you in the warmed houses at Kew ; laurel-like leaves, a tropical kind of oak, maple, smilax, aralia, yew, palms, and a fern. These have been selected to show the great diversity in the shapes which existed.

Most people are familiar with the process of skeletonising leaves - that is, the removal of the green part, and the preservation of what is called the skeleton. I have here a large case of leaves so prepared by Mrs. J. E. Gardner, and which may be examined at the close of the lecture.

I would next draw attention to some leaves of trees which are well known as now growing in England. In these a continuation of the leaf-stalk can clearly be distinguished running through the leaf, which is commonly called the mid-rib. [The mid-ribs in two diagrams were co'oured red.] Those running from the primary ribs are called secondary ribs (coloured blue). There are, again, running from these many smaller portions, which are called the network of the skeleton. In some, as, for example, the plane-tree, there are three primary ribs; in a few leaves 